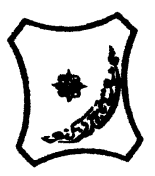

Bayero Journal of Pure and Applied Sciences, 10(1): 126 - 132

ISSN 2006 - 6996

\title{
EFFECT OF BIOCIDES ON BIOFILMS OF SOME MULTIDRUG RESISTANT CLINICAL BACTERIAL ISOLATES
}

\author{
Shittu, A. S. and Ja'afaru, M. I.* \\ Department of Microbiology, Modibbo Adama University of Technology, PMB 2076, Yola. Nigeria. \\ "Corresponding author: mijaafaru@mautech.edu.ng
}

\begin{abstract}
The biofilm production ability of some multidrug resistant clinical bacterial isolates was determined in the presence of four biocides - chlorhexidine gluconate (3\%), cetrimide (0.75\%), sodium hypochlorite (3.5\%) and chloxylenol BPC (3.8\%) - using the modified microplate method. The multi drug resistant clinical isolates used in this study are Staphylococcus aureus, Pseudomonas aeruginosa, Escherichia coli, Klebsiella aerogenes, Proteus mirabilis and Citrobacter freundii. These bacteria showed resistance to at least 5 antibiotics. Quantitative microtiter plate assay showed that 24 (58.55\%) out of the 41 biofilms producers produced strong biofilms with optical density ranging from 0.25 to 0.35 . The result demonstrated that sodium hypochlorite was more effective in inhibiting biofilm formation in the bacterial isolates. Lower concentrations of the biocides were more effective in inhibiting biofilm formation by bacteria. The ability of Escherichia coli and Klebsiella aerogenes to form biofilms was most affected. There was little inhibition of biofilm formation by the biocides on Staphylococcus aureus. This study has shown a relationship between biocide and multidrug resistance.

Key words: Biocides, Multi drug resistance, sodium hypochlorite, Staphylococcus aureus
\end{abstract}

\section{INTRODUCTION}

Nosocomial infections are increasingly becoming significant in healthcare environments. There have been reports of rise in hospital acquired infections by multi-drug resistant microorganisms (Smith and Hunter, 2008). Biofilm production is an important factor in infections caused by micro-organisms. Biofilms comprise of a functional consortium of cells encased in hydrated polymeric matrix. Adhesion to surfaces in biofilms by micro-orgnisms is a form of survival mechanism in hostile environment (Watnick and Kolter, 2000). The biofilm structure protects the cells from dehydration and other environmental pressures while allowing the organisms to persist in a conducive environment (Donlan and Costeron, 2002). Biofilms can form on any living or non-living surface. Within the biofilm matrix, micro-organisms show increased resistance to antimicrobials and biocides and also serve as reservoirs of pathogens in the hospital causing for a high percentage of nosocomial infections (Song et al., 2012). Biofilms have been reported in many medical devices such as implants and catheters (Hatch and Schiller, 1998). Evaluating the effects of some biocides used in hospitals to eradicate cells growing in biofilms becomes imperative.

The use of biocides in biofilm control is common and accepted. Biocides are broadspectrum and multitargeted compounds that inactivate micro-organisms on living tissues and inanimate surfaces ( $\mathrm{Oz}$ et al., 2012). They are used on medical devices to limit contamination. This study investigated the effects of some biocides on biofilm production and antibiotic resistance patterns of some bacteria isolated from clinical samples in Yola, Nigeria.

\section{MATERIALS AND METHODS}

Isolates

Bacterial isolates were obtained from urine, wound and ear at the Federal Medical Centre, Yola, Nigeria. The isolates were identified on the basis of standard and conventional microbiological techniques and the characteristics compared with those of known taxa as described by Collee et al. (1999). 


\section{Antibiotic Susceptibility Test}

The antibiotic sensitivity test of the isolates was done following the Kirby-Bauer disc diffusion method recommended by the National Committee for Clinical Laboratory Standard (NCCLS, 2002) using Mueller Hinton agar. The suspension of the organisms in nutrient broth was adjusted to match the 0.5 Mcfarland turbidity standards and standard commercial antibiotic discs containing ampicillin $(10 \mu \mathrm{g})$, ciprofloxacin $(10 \mu \mathrm{g})$, chloramphenicol $(30 \mu \mathrm{g})$, tetracycline $(30 \mu \mathrm{g})$, gentamicin $(10 \mu \mathrm{g})$, erythromycin $(15 \mu \mathrm{g})$, ofloxacin $(10 \mu \mathrm{g})$, streptomycin $(30 \mu \mathrm{g})$, amoxicillin $(30 \mu g)$ were used.The sizes of the zones of inhibition were interpreted by referring to zone size interpretative chart of the NCCLS and the organisms are reported as susceptible, intermediate or resistant to the agents that have been tested(NCCLS, 2002; Cheesebrough, 2006).

Phenotypic Detection of Biofilm Production on Congo Red Agar

Biofilm forming colony morphology was detected on Congo Red Agar (CRA) as described by Arciolaet al. (2005). Bacteria were first grown in $10 \mathrm{ml}$ tryptic soy broth containing $0.25 \%$ glucose at $37^{\circ} \mathrm{C}$ for $24 \mathrm{~h}$ without shaking and then plated to CRA plate. The plates were then incubated at $37^{\circ} \mathrm{C}$ for $24 \mathrm{hr}$. An additional incubation for $24 \mathrm{hr}$ was done at room temperature $\left(25^{\circ} \mathrm{C}\right)$ before recording the colony morphology. Crusty black colonies with dry filamentous appearance were recorded as biofilm producers, while smooth pink colonies were recorded as non-producers.

Quantitative Determination of Biofilm Production

Quantitative determination of biofilm production was carried out using the microtiter method of Freeman et al. (2001). Overnight grown bacteria in nutrient broth containing $0.25 \%$ glucose were diluted to 1 in 100 and $200 \mu$ portions were inoculated into 96 - well flat bottom polystyrene microtiter plates (cellstar, greiner bio one). Incubation was carried out at $37^{\circ} \mathrm{C}$ for $22-24 \mathrm{~h}$ before removal of the cultures. The wells were washed three times with phosphate buffered saline (PBS, $\mathrm{pH} 7.2$ ), air dried and stained with $0.1 \%$ safranin. The optical density of the wells was measured at $650 \mathrm{~nm}$ using micro Elisa auto reader (Stat Fax 2100, Awareness Technol. Inc. Japan). An optical density range of 0.12 to 0.35 was chosen to distinguish weak biofilm producers from strong biofilm producers. A well containing growth medium without bacteria was also included as control.

\section{Biocides}

Biocides that were used for the study are Moricet[Chlorhexidine gluconate $(3.3 \% \mathrm{w} / \mathrm{v})$ and Cetrimide $(0.75 \%)$ ], Hypo [Sodium Hypochlorite $(3.5 \% \mathrm{w} / \mathrm{v})$ ] and Dettol [Chloroxylenol B.PC. (3.8\% $\mathrm{w} / \mathrm{v})]$.

Effect of Biocides on Biofilm formation

A microtiter plate was used to determine the inhibition of biofilm production. Bacteria were grown on tryptic soy agar containing $0.2 \%$ glucose after which they were re-suspended in tryptic soy broth plus $0.2 \%$ glucose and the optical density of suspension at $650 \mathrm{~nm}\left(0 . \mathrm{D}_{650}\right)$ was adjusted to 0.1 . Then $180 \mu \mathrm{l}$ of the bacterial suspension was inoculated in six parallel wells of a 96-well microtiter plate. Appropriate volume of each biocide (in various concentrations) was added to the microtitre plate wells. Positive control wells had $180 \mu \mathrm{l}$ bacterial suspension and negative control wells contained only $180 \mu$ tryptic soy broth plus $0.2 \%$ glucose. After incubation for $24 \mathrm{~h}$ at $37^{\circ} \mathrm{C}$, the content of each well was aspirated and each well washed with sterile phosphate buffered saline three times to remove all nonadherent cells. Attached bacteria were fixed with absolute methanol for $10 \mathrm{~min}$. Later the plates were stained for $20 \mathrm{~min}$ with crystal violet $1 \%$ $\mathrm{w} / \mathrm{v}$ ), excess stain washed off and the plates rinsed with tap water. After the plate was airdried, the dye bound to biofilm formation of tested bacteria was resolubilized with $33 \%(\mathrm{v} / \mathrm{v})$ glacial acetic acid. The O.D of each well was measured at $650 \mathrm{~nm}$ by using an ELISA reader and the relative inhibition of biofilm (expressed as mean percentage inhibition) was calculated: using the formula given below as described byKhani-Juyet al.(2009).

Percentage growth Inhibition $=100-\frac{O D_{650} \text { of bicoide containing well }}{O D_{650} \text { of control well }} \times 100$

Data Analysis

The data was analysed statistically using one way analysis of variance (ANOVA) to determine the relationship in terms of biofilm production and biocide effectiveness. 


\section{RESULTS AND DISCUSSION}

Bacteria isolated from specimens

In this study, 168 bacterial isolates were recovered from the specimens processed after isolation and identification. Among the Gram positive isolates, Staphylococcus aureus was predominant while Escherichia coli, Pseudomonas aeruginosa, Klebsiella aerogenes, Proteus mirabilis, Proteus vulgaris and Citrobacter freundii were the Gram negative isolates. These isolates are clinically significant pathogens, and are similar to those reported by Al-Sweih (2008) in Kuwait and Mordi and Erah (2006) in Benin, Nigeria. According to CDC (2000), S. aureus is the most prevalent organism associated with wound and ear infection.

Antibiotic Susceptibility Patterns of Bacterial isolates

The result of antimicrobial susceptibility pattern of the isolates is shown in Table 1. Staphylococcus aureus isolates from all the samples were deemed highly resistant to most of the antibiotics tested showing high rate of multidrug resistance. Among the $59 \mathrm{~S}$. aureus isolates, $78 \%, 66 \%, 73 \%$ and $68 \%$ were resistant to gentamicin, ofloxacin, chloramphenicol, ampiclox and ampicillin respectively. Thirteen (68.1\%) isolates of Pseudomonas aeruginosa were resistant to gentamicin and chloramphenicol, $59 \%$ to ampiclox and $63 \%$ to ampicillin. For Escherichia coli $53.8 \%$ isolates were resistant to gentamicin, chloramphenicol and ampiclox while $58 \%$ were resistant to ampicillin. Ten (77\%) isolates of Proteus mirabilis were resistant to ampiclox, 69\% resistant to tetracycline, $61.5 \%$ resistant to ampicillin and $84.6 \%$ resistant to ofloxacin. Marked resistance to ampiclox, chloramphenicol and gentamicin was reported in a study by Okonko et al. (2009). Majority of the S. aureus $(52.5 \%)$ were multi-drug resistant and these multi-drug resistance pattern had been documented by Maiti et al. (2006) and Okesolet al. (2009). The present study highlights the alarming situation of antibiotics resistance in bacteria. Such multidrug resistance has important implications for the empiric therapy of infections caused by S. aureus, P. aeruginosa, E. coli, K. aerogenes, $P$. mirabilis and $C$. freundii and for the possible co-selection of antimicrobial resistance mediated by multidrug resistance plasmids (Okesol et al., 2009).

Biofilm Production Ability among the Bacterial Isolates

A total of 72 isolates of multi-drug resistant $S$. aureus, $P$. aeruginosa, $K$. aerogenes, $E$. coli, $P$. mirabilis and C. freundii were investigated for biofilm production on CRA. Among the 72 isolates, 48 were found to produce biofilm at $37^{\circ} \mathrm{C}$ developing black colonies while 41 of the 48 isolates produced crusty black colonies after further incubation for another $24 \mathrm{~h}$ at room temperature $\left(25^{\circ} \mathrm{C}\right)$ and were considered to be biofilm producers. Eight (8) isolates developed faint black colonies at room temperature. Twenty four (24) out of the 72 isolates were non biofilm producers both developing smooth pink colonies at both $37^{\circ} \mathrm{C}$ and $25^{\circ} \mathrm{C}$. The result indicates that most of the multidrug resistant isolates were able to produce biofilm (Table 2). The quantitative microtiter plate assay result presented in Table 3 showed that 24 (58.55\%) out of the 41 biofilms producers produced strong biofilms with optical density ranging from 0.25 to 0.35 while $18(43.9 \%)$ isolates produced weak biofilms with optical density ranging from 0.12 to 0.24 . Eleven $(45.8 \%)$ S. aureus isolates produced strong biofilms while 9 (37.5\%) produced weak biofilms. Three each of $E$. coli and $K$. aerogenes isolates $(12.5 \%)$ produced strong biofilm. This result indicates that not all the bacterial isolates that form crusty black colonies on CRA plates at both $37^{\circ} \mathrm{C}$ and $25^{\circ} \mathrm{C}$ produced strong biofilms. Thus, some were found to be weak biofilm producers. For biofilm formation to occur, synthesis of an intercellular polysaccharide adhesin (PIA) is necessary to mediate cell-to-cell adhesion. This PIA is synthesized by the gene products of the icaADBC locus (Crampton et al., 1999; Mckennyet al., 1999). Crampton et al. (1999) suggested that biofilm negative phenotype in S.aureus, P. aeruginosa; E. coli, K. aerogenes, $P$. mirabilis and $C$. freundii resulted from the deletion of ica operon. The initial adhesion of bacterial cells to the polymer surface was influenced by environmental conditions (Mckennny et al., 1999). However the initial microbial adhesion cannot be achieved without considering the effect of the substrate, various properties of the cell surface and characteristics of the aqueous medium such as ionic strength, temperature and $\mathrm{pH}$ (Hamadi et al., 2004).

Effect of biocides on biofilm formation

The results in Figures 1, 2 and 3 showed the inhibitory effect of biocides against bacteria biofilm formation at different concentrations. Result showed that $3.5 \%$ sodium hypochlorite significantly inhibited the growth of $E$. coli biofilm at a percentage inhibition of $90.6 \%$ and its biocide well has the lowest optical density of 0.003 (Figure 1). 
This was followed by $K$. aerogenes and $C$. freundiiwhose growth were inhibited at a percentage of 87.6 at the same concentration and the O.D of their biocide well was recorded as 0.004 . Chloroxylenol at a concentration of $3.8 \%$ had its highest percentage growth inhibition of $81.8 \%$ for E. coli and lowest O.D of biocide well is 0.006 (Figure 2). This was followed by $P$. aeruginosa whose growth was inhibited at a percentage of $74.2 \%$ and O.D of 0.008 for biocide well.

Chlorhexidine gluconate had the least effect on the biofilm among the three biocides. At a concentration of $3.3 \%$, chlorhexidine gluconate had the highest percentage growth inhibition of $69.7 \%$ on $K$. aerogenesbiofilm at an O.D of 0.009 (Figure 3). This was followed by $E$. coli with a percentage inhibition of $63.6 \%$ and O.D of 0.012 . The ability to inhibit biocide formation increases with decrease in biocide concentrations. S. aureus was the least inhibited organism at all concentrations by chloroxylenoland chlohexidine gluconate. Inhibition of biofilm formation by the biocides was most effective for $E$. coli and $K$. aerogenesisolates.Sodium hypochlorite (hypo) was found to be more effective than chloroxylenol (dettol) and chlorhexidine gluconate (moricet) in inhibiting the growth of bacterial biofilms. At $P \leq 0.05$, there is significant difference in inhibition of biofilm growth among the biocides. Chloroxylenolhas been reported to inhibit S. epidermidis isolates more effectively than $P$. aeruginosain biofilms (Pitts et al., 2003). Crampton et al. (1999) also reported that local treatment with $3 \%$ sodium hypochlorite and chlorhexidine gluconate reduced biofilm growth by more than $79 \%$ on polymer biomaterials. Poor biocides penetration has also been described for biofilms resistance (Anderlet al., 2000).

Resistance to biocide has gained an increasing interest as studies have reported biocideantibiotic cross-resistance (Stickler, 2002). Analysis of antibiotic resistance patterns and antiseptic sensitivity of biofilms to biocides revealed a remarkable relationship between resistant to biocide and multidrug resistance. When antibacterial targets are shared between biocide and antibiotic selection, pressure of the first can provoke resistance to the latter (Russell et al., 2002).

This study has highlighted the effect of biocides on the bacterial biofilm formation. None of the biocides was able to kill $100 \%$ of cells in the biofilm formed by the multi-drug resistant isolates of S. aureus, $P$. aeruginosa, $E$. coli, $K$. aerogenes, $P$. mirabilis and $C$. freundii. This suggests that when these biocides are used, they fail to eradicate bacterial biofilms, leaving a survivor population to provide a reservoir for the spread and preservation of the infectious agent.

Table 1: Antimicrobial susceptibility profile of bacterial isolates from various clinicalspecimens in Yola, Nigeria

\begin{tabular}{|c|c|c|c|c|c|c|c|c|c|c|c|c|c|c|c|c|c|c|c|c|}
\hline \multirow[t]{2}{*}{ Bacterial Isolates } & \multicolumn{2}{|c|}{ CPX } & \multicolumn{2}{|c|}{ STR } & \multicolumn{2}{|c|}{ ERY } & \multicolumn{2}{|c|}{$\mathrm{AMX}$} & \multicolumn{2}{|c|}{ GEN } & \multicolumn{2}{|l|}{$\mathrm{CH}$} & \multicolumn{2}{|c|}{ APX } & \multicolumn{2}{|c|}{ TET } & \multicolumn{2}{|c|}{ AMP } & \multicolumn{2}{|c|}{ OFX } \\
\hline & $\mathrm{R}$ & $\mathrm{S}$ & $\mathrm{R}$ & $\mathrm{S}$ & $\mathrm{R}$ & $S$ & $\mathrm{R}$ & $S$ & $\mathrm{R}$ & $S$ & $\mathrm{R}$ & $S$ & $\mathrm{R}$ & $S$ & $\mathrm{R}$ & $S$ & $\mathrm{R}$ & $S$ & $\mathrm{R}$ & $S$ \\
\hline S. aureus $(\mathrm{n}=59)$ & 15 & 44 & 26 & 39 & 12 & 47 & - & - & 46 & 13 & 39 & 20 & 43 & 16 & - & - & 40 & & 39 & 20 \\
\hline P. aeruginosa $(\mathrm{n}=19)$ & 4 & 15 & - & - & - & - & 7 & 12 & 13 & 6 & 13 & 6 & 11 & 8 & 6 & 13 & 12 & 19 & 9 & 10 \\
\hline E. $\operatorname{coli}(\mathrm{n}=26)$ & 10 & 16 & - & - & - & - & 8 & 18 & 14 & 12 & 14 & 12 & 14 & 12 & 3 & 23 & 15 & 7 & 11 & 14 \\
\hline K. aerogenes $(n=25)$ & 14 & 11 & - & - & - & - & 10 & 15 & 6 & 19 & 18 & 7 & 12 & 13 & 19 & 6 & 8 & 11 & 23 & 2 \\
\hline P. mirabilis $(\mathrm{n}=13)$ & 4 & 9 & - & - & - & - & 3 & 10 & 5 & 8 & 2 & 11 & 10 & 3 & 9 & 4 & 8 & 17 & 11 & 2 \\
\hline C. freundii $(\mathrm{n}=13)$ & 9 & 4 & - & - & - & - & 8 & 5 & 7 & 6 & 9 & 4 & 3 & 10 & 3 & 10 & 11 & 5 & 5 & 8 \\
\hline P. vulgaris $(n=3)$ & 0 & 3 & - & - & - & - & 0 & 3 & 1 & 2 & 0 & 3 & 1 & 2 & 0 & 3 & 0 & $\begin{array}{l}2 \\
3\end{array}$ & 0 & 3 \\
\hline
\end{tabular}

KEY: $\quad$ CPX - Ciprofloxacin STR - Streptomycin ERY - Erythromycin APX - Ampiclox
AMX - Amoxicillin GEN - Gentamicin $\mathrm{CH}$ - Chloramphenicol
TET - Tetracycline AMP - Ampicillin OFX - Ofloxacin
R - Resistant Not tested
$\mathrm{S}$ - Susceptible 
Table 2:Morphological appearance of biofilm on Congo Red Agar (CRA)

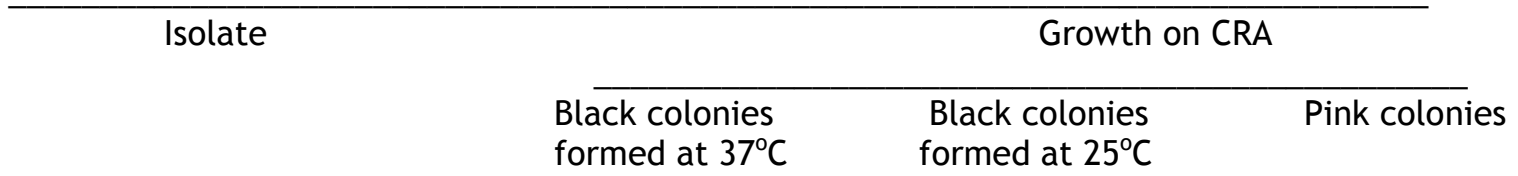

\begin{tabular}{lccc}
\hline S. aureus $(\mathrm{n}=32)$ & 23 & 20 & 9 \\
P. aeruginosa $(\mathrm{n}=13)$ & 8 & 7 & 5 \\
E. coli $(\mathrm{n}=9)$ & 6 & 4 & 3 \\
K. aerogenes $(\mathrm{n}=7)$ & 4 & 4 & 3 \\
P. mirabilis $(\mathrm{n}=6)$ & 4 & 3 & 2 \\
C. freundii $(\mathrm{n}=5)$ & 3 & 3 & 2 \\
Total $\quad 72$ & 48 & 41 & 24 \\
\hline
\end{tabular}

Table 3: Spectrometric determination of biofilm production at $650 \mathrm{~nm}$

\begin{tabular}{lll}
\hline Biofilm isolates & Strong biofilms & Weak biofilms \\
\hline S. aureus $(\mathrm{n}=20)$ & 11 & 9 \\
P. aeruginosa $(\mathrm{n}=7)$ & 4 & 3 \\
E. coli $(\mathrm{n}=4)$ & 3 & 1 \\
K. aerogenes $(\mathrm{n}=4)$ & 3 & 1 \\
P. mirabilis $(\mathrm{n}=4)$ & 2 & 2 \\
C. freundii $(\mathrm{n}=3)$ & 1 & 2 \\
Total $\quad 41$ & 24 & 18 \\
\hline
\end{tabular}

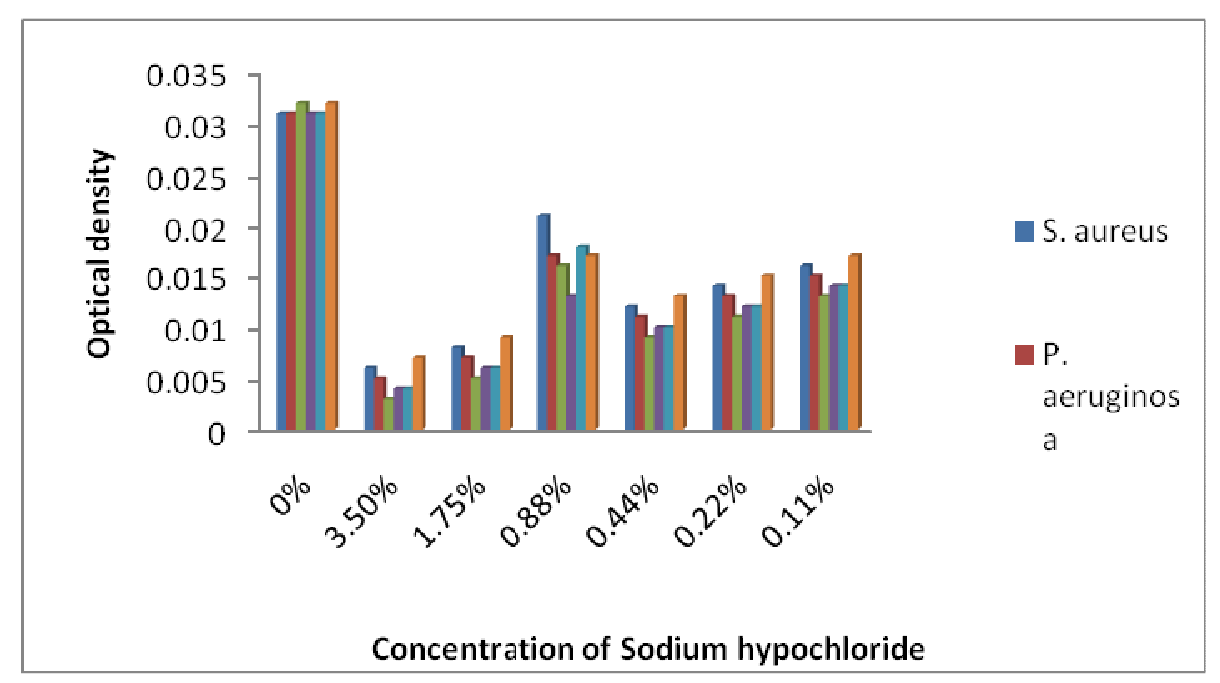

Figure 1:Inhibition of biofilm formation of selected bacterial isolates in presence of sodium hypochlorite 


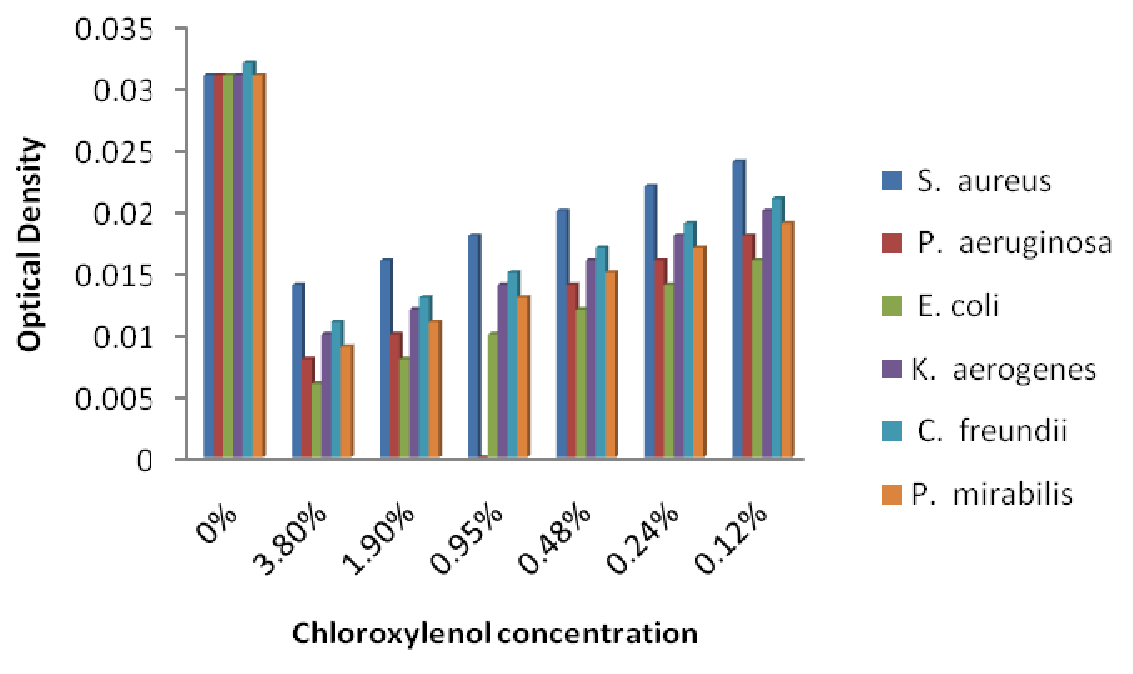

Figure 2:Inhibition of biofilm formation of selected bacterial isolates in presence of chloroxylenol

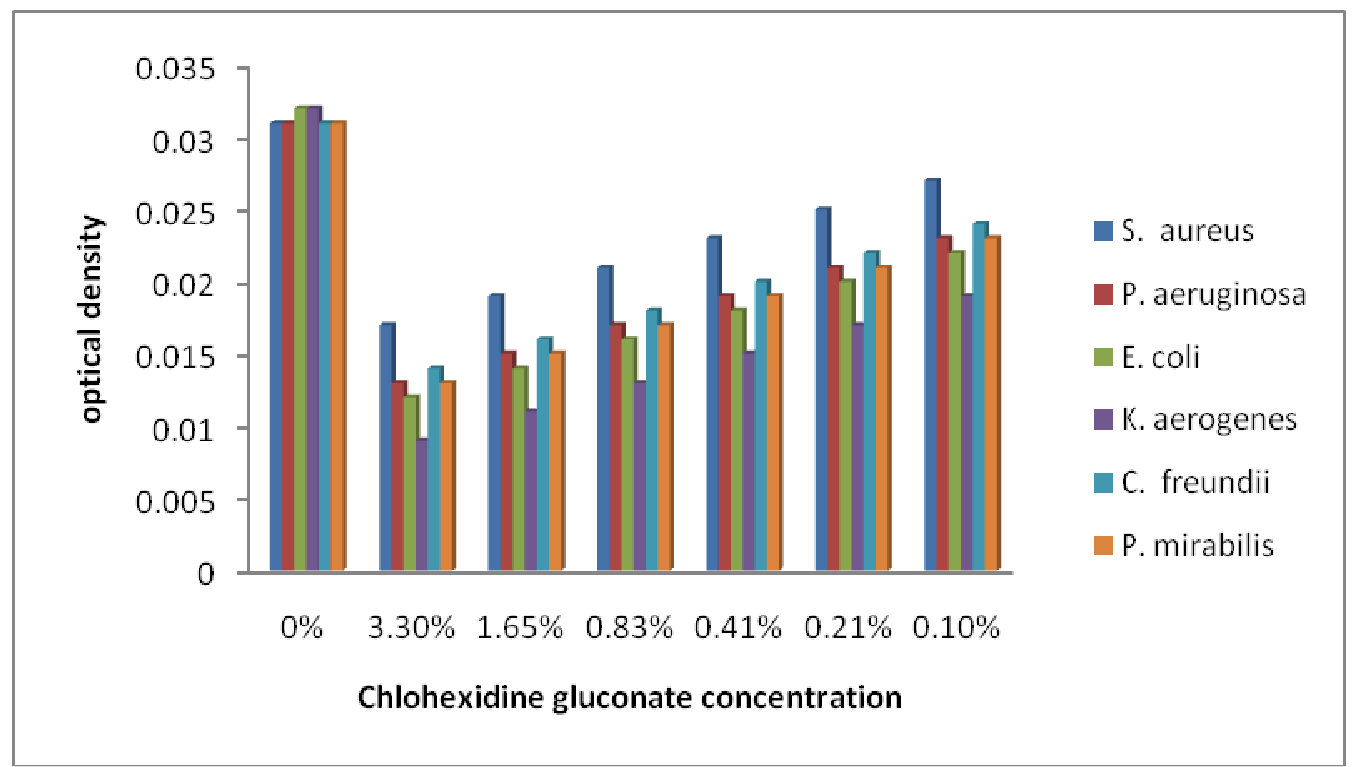

Figure 3:Inhibiton of biofilm formation of selected isolates in presence of chlorhexidine gluconate

\section{REFERENCES}

Al-Sweih, N. (2008). Antimicrobial susceptibility of pathogenic bacteria causing urinary tract infections.Journal of Medical Microbiology. 45:90-95.

Anderl, J. A., Stewart, P.S., Franklin, M. J. (2000). Role of antibiotic penetration limitation in Klebsiellaaerogenes biofilm resistance to ampicillin and ciprofloxacin.Antimicrobial Agents and Chemotherapy. 44: 187-1824.

Arciola, C. R., Compoccia, D., Baldassari, L., Donati, M. E., Pirini, V., Gamberini, S., and Montanaro, L. (2005). Detection of biofilm formation in Staphylococcus epidermidis from implant infections. Comparison of a PCR method that recognizes the presence of icagenes with two classic phenotypic methods. Journal of Biomedical

Material Research.76A(2):425-430

Cheesbrough, M. (2006).Medical Microbiology: Manual for Tropical Countries. $10^{\text {th }}$ edition. Butterworth- Heinemann Ltd. 2. pp: 289-310.

Collee, J.G., Traser, A.G., Marnion, B.P. (1999).Mackie and McCartney Practical Medical Microbiology, $14^{\text {th }}$ edition.ChurchillLiving stone publishers. pp: 131-150. 
Special Conference Edition, November, 2017

Crampton, S. E., Gerke, C., Schnell, N.F., Nichols, W. W., Goltz, F. (1999). The intercellular adhesion locus present in biofilms. Infectious Immunology. 67:5427-5433.

Donlan, R.M. and Costerton, J.W. (2002).Biofilms; Survival mechanisms of chemically relevant microorganisms.Clinical Microbiology Review. 15:167-193.

Freeman, D.J., Falkiner, F.R., Keane, C. T. (2001). New method for detecting slime production by coagulase negative Staphylococci.Journal of Clinical Pathology. 42:872-874.

Hamadi, F., Latrache, H., ElGhmari, A., Mabrouki, M., ElloualimKuider, N. (2004). Effect of $\mathrm{PH}$ and lonic strength on hydrophobicity and electron donor and acceptor characteristics of Escherichia coli and Staphylococcus Microbiology.54: 213-225.

Hatch, R. A. and Schiller, N. I. (1998) Alginate lyase promotes diffusions of aminoglycosides through the extracellular polysaccharide of mucoid Pseudomonas aeruginosa. Antimicrobial agents and chemotherapy. 42:974-977

Khani-Juy, A. F., Abdi-Ali, A. andGharavi, S. (2009) Antibiofilm activities of certain biocides in Pseudomonas aeruginosa.Iranian Journal of Microbiology.1(4):23-27

Maiti, P.K. (2006). Detection of biofilm.Indian Journal of Medical Microbiology. 24:303.

Mckenny, D., Ponliot, D.L., Wang, Y., Murthy, V., Ulrich, M. (1999).Broadly protective vaccine for Staphylococcus aureus based on an in vivo expressed antigen.Science. 284:1523-1527.

Mordi, R.M. and Erah, P.O. (2006). Susceptibility of common urinary tract isolates to the commonly used antibiotics in a tertiary hospital in Southern Nigeria. African Journal of Biotechnology. 5(11):21-25.

National Committee for Clinical Laboratory Standards (NCCLS) (2002).Performance standardsfor antimicrobial susceptibility testing.8thinformational supplement. M100512. Villanous, $\mathrm{Pa}$.

Okesol, A.O., Oni, A.A. (2009). Antimicrobial resistance among bacterial pathogens in South Western Nigeria.American Eurasian Journal of Agriculture and Environmental Science. 5(3): 327-330.

Okonko, I.O., ljandife, L.A., Ilusanya, A.D., Okeke, N.A. (2009). Detection of Urinary Tract Infection among women in Oluyoro Catholic Hospital Ibadan.Malaysian Journal of Microbiology. 6(1):16-24.

Oz, Y., Dag, I. and Kiraz, N. (2012) Efficacy of disinfectants on Candida biofilms at different concentrations and contact time. British Microbiology Research Journal.2(2):40-52

Pitts, B., Hamilton, M.A., Zelver, N., Stewart, P.S. (2003). A microtiter-plate screening method for biofilm disinfection and removal.Journal of Microbiological methods.54: 269-276.

Russell, A. D. (2002) Antibiotics and biocide resistance in bacteria: Introduction. Journal of Applied Microbiology. 92:1S35

Smith, K. and Hunter, I. S. (2008) Efficacy of common hospital biocides with biofilms of multi-drug resistant clinical isolates. Journal of Medical Microbiology. 57:966973

Song, L., Jianfeng, W. and Chuanwu, X. (2012). Biofilms on environmental surfaces: Evaluation of the disinfection efficacy of a novel steam vapor system.American Journal of Infection Control.http://dx.doi/10.1016/j.ajic.20 11.11.013

Stickler, D.J. (2002). Susceptibility of antibiotic resistant Gram position bacteria to biocides: a perspective from the study of catheter biofilms. Sympsersoc Applied Microbiology. 31: 1635-1705.

Watnick, P. and Kolter, R. (2000).Biofilm, a city of microbes.Journal of Bacteriology. 182(10):2675-2679 